\title{
Clinical Significance of Elevated Serum Immunoglobulin G4 Levels in Patients With Rheumatoid Arthritis
}

\author{
Sang-Hyon Kim, M.D., Ph.D. ${ }^{1}$, Hye-Jin Jeong, M.D. ${ }^{1}$, Ji-Min Kim, M.D., Ph.D. ${ }^{1}$, Jae-Bum Jun, M.D., Ph.D. ${ }^{2}$, \\ Chang-Nam Son, M.D., Ph.D. ${ }^{1}$ \\ ${ }^{1}$ Division of Rheumatology, Department of Internal Medicine, Keimyung University School of Medicine, Daegu, ${ }^{2}$ Department of Rheumatology, \\ Hanyang University Hospital for Rheumatic Diseases, Seoul, Korea
}

\begin{abstract}
Objective. This study aimed to evaluate the relationship between serum immunoglobulin G4 (IgG4) levels and the presence and disease activity of rheumatoid arthritis (RA). Methods. The study enrolled 128 participants (RA, 96; healthy controls, 17; osteoarthritis, 11; and IgG4-related disease, 4) between March 2014 and July 2017. Blood samples were collected prior to the commencement of treatment, and serum IgG4 levels were determined using a nephelometric assay (levels $\geq 135 \mathrm{mg} / \mathrm{dL}$ were considered elevated). The levels of serum IgG4 and the ratio of IgG4/total IgG in patients with RA were compared with those in healthy controls, patients with osteoarthritis, and patients with IgG4-related disease. Furthermore, the relationship between serum IgG4 levels and RA disease activity was evaluated. Results. Among the 96 patients with RA, the mean ( \pm standard deviation) serum IgG4 level was $48.0 \pm 45.4 \mathrm{mg} / \mathrm{dL} ; 6$ (6.3\%) patients had elevated serum IgG4 levels. However, none of the healthy controls or patients with osteoarthritis had elevated serum IgG4 levels. The mean serum IgG4/IgG ratio in patients with RA was $3.5 \% \pm 2.8 \%$ (range, $0.2 \% \sim 16.9 \%$ ). Using Spearman's correlation coefficient analysis, a significant correlation was found between serum IgG4 levels and the Disease Activity Score-28 with erythrocyte sedimentation rate $(r, 0.245 ; p=0.016)$. Conclusion. There was an increased frequency of elevated serum IgG4 levels in patients with RA, and the levels were correlated with RA disease activity. (J Rheum Dis 2020;27:96-99)
\end{abstract}

Key Words. Rheumatoid arthritis, Immunoglobulin G4

\section{INTRODUCTION}

Rheumatoid arthritis (RA) is a chronic, progressive, autoimmune disease characterized by joint pain and swelling and is associated with functional disability [1]; its diagnostic determinants include the presence of rheumatoid factor and anticyclic citrullinated peptide antibodies [2]. Disease activity is evaluated using serum inflammatory markers, such as erythrocyte sedimentation rate (ESR) and C-reactive protein (CRP) levels, and the Disease Activity Score-28 (DAS28) [3]. However, these diagnostic and disease-activity markers are insufficient for establishing an RA diagnosis and the associated treatment protocol.
Immunoglobulin-4 (IgG4) is the least common of the 4 IgG subclasses and is associated with several autoimmune diseases $[4,5]$. IgG4-related diseases (IgG4-RDs) (e.g., Mikulicz disease, autoimmune pancreatitis, and Kuttner's tumor) are systemic, chronic, inflammatory diseases characterized by elevated serum IgG4 levels and IgG4-secreting plasmacytes invading the visceral tissues [6]. In Japan, IgG4-RDs are common, with a prevalence of $0.28 \sim 1.08$ per 100,000 people $[7,8]$. Recently, interest into the field of IgG4-RDs has developed in various departments. Studies on IgG4-RD have reported elevated serum IgG4 levels in certain rheumatic diseases, such as systemic sclerosis [9].

In this study, we investigated the relationship between

\footnotetext{
Received : September 4, 2019, Revised : (1st) December 18, 2019, (2nd) January 14, 2020, Accepted : January 14, 2020

Corresponding to : Chang-Nam Son (1D http://orcid.org/0000-0002-1722-2190

Division of Rheumatology, Department of Internal Medicine, Keimyung University School of Medicine, 1035 Dalgubeol-daero, Dalseo-gu, Daegu 42601, Korea. E-mail : cnson@kmu.ac.kr
} 
serum IgG4 levels and the presence and disease activity of RA.

\section{MATERIALS AND METHODS}

\section{Patients}

Between March 2014 and July 2017, 128 individuals (RA, 96; healthy controls, 17; osteoarthritis, 11; and IgG4-related disease, 4) from Keimyung University Dongsan Hospital in Daegu were enrolled into this study. Patients diagnosed as having RA met the 1987 American College of Rheumatology (ACR) criteria [10] or the 2010 ACR/European League Against Rheumatism (EULAR) criteria for RA [2]. Those with IgG4-RDs, those with OA, and the healthy individuals comprised the comparator. Participant blood samples were collected prior to the commencement of any medical treatment. The collected data for the patients with RA included clinical variables and disease activity markers, such as the number of tender and swollen joints, serum levels of acute-phase reactants, and DAS28 scores. Patients were divided into either a high disease-activity (HDA) group (DAS28 $\geq 5.1$ ) or a remission/low disease activity (LDA)/moderate disease activity (MDA) group (DAS28 < 5.1).

The study was approved by the Institutional Review Board of Keimyung University Dongsan Hospital (approval number, 2014-12-009) and was conducted in accordance with the Declaration of Helsinki. Written informed consent was obtained from all study participants.

\section{Serum total $\lg G$ and $\operatorname{lgG} 4$}

Venous blood samples, obtained from all participants, were immediately processed in a centrifugal separator at $120,000 \mathrm{rpm}$ for 20 minutes. Prior to serum IgG and IgG4 measurements, the separated sera were stored at $-70^{\circ} \mathrm{C}$. Serum total IgG and IgG4 levels were determined using nephelometry (Spa Plus; Binding Site, Birmingham, UK) with human IgG and IgG subclass liquid reagent kits
(Binding Site). Total IgG levels $>1,600 \mathrm{mg} / \mathrm{dL}$ or IgG4 levels $\geq 135 \mathrm{mg} / \mathrm{dL}$ were considered elevated $[5,6]$.

\section{Statistical analysis}

Data handling and statistical analyses were performed using SPSS (version 20.0; IBM Co., Armonk, NY, USA). Results obtained from the analyses are presented as means \pm standard deviations. The non-parametric MannWhitney U-test was used to compare serum total IgG levels, serum IgG4 levels, and IgG4/total IgG ratios between the patient and control groups. Values for patients with RA were compared to those from patients with IgG4-RD (positive control), healthy individuals and patients with OA (negative controls). Spearman's rho was used to determine the correlation between serum IgG4 levels and indicators of RA disease activity; p-values $<0.05$ were considered significant.

\section{RESULTS}

Table 1 summarizes the study participants' characteristics (RA, 96; healthy controls, 17; OA, 11; and IgG4-RD, 4). Among the 96 patients with RA, the mean serum IgG4 level was $48.0 \pm 45.4 \mathrm{mg} / \mathrm{dL}$, including $6(6.3 \%)$ with elevated serum IgG4 levels. The mean serum IgG4/IgG ratio in patients with RA was $3.5 \% \pm 2.8 \%$ (range, $0.2 \% \sim 16.9 \%$ ), and patients with IgG4-RD had high levels of serum IgG4 (717.38 \pm 772.17$)$. Conversely, none of the participants in the control group had elevated serum IgG4 levels. However, statistically significant differences in the serum IgG4 levels and the IgG4/total IgG ratios were not observed between patients with RA and healthy controls.

Elevated serum IgG4 levels were found in $3(10.7 \%)$ individuals in the HDA group $(\mathrm{n}=28)$ and in $3(4.4 \%)$ individuals in the remission/LDA/MDA group $(n=68)$. However, statistically significant differences were not observed in serum IgG4 levels between the HDA and remission/LDS/MDA groups (data not shown). According

Table 1. Study participant characteristics

\begin{tabular}{lcccc}
\hline \hline \multicolumn{1}{c}{ Diseases } & $\operatorname{lgG}(\mathrm{mg} / \mathrm{dL})$ & $\operatorname{lgG} 4(\mathrm{mg} / \mathrm{dL})$ & $\operatorname{lgG} / \operatorname{lgG}(\%)$ & $\begin{array}{c}\text { Patients with elevated } \\
\text { IgG4 levels }(>135 \mathrm{mg} / \mathrm{dL})\end{array}$ \\
\hline IgG4-related disease $(\mathrm{n}=4)$ & $3,092.50 \pm 662.89$ & $717.38 \pm 772.17$ & $24.33 \pm 24.76$ & $3(75)$ \\
Rheumatoid arthritis $(\mathrm{n}=96)$ & $1,330.94 \pm 397.57$ & $48.01 \pm 45.39$ & $3.40 \pm 2.48$ & $6(6.25)$ \\
Osteoarthritis $(\mathrm{n}=11)$ & $1,078.18 \pm 148.01$ & $34.01 \pm 22.89$ & $3.38 \pm 2.61$ & 0 \\
Healthy controls $(\mathrm{n}=17)$ & $1,525.30 \pm 493.86$ & $35.7 \pm 29.52$ & $2.48 \pm 2.03$ & 0 \\
\hline
\end{tabular}

Values are presented as mean \pm standard deviation or number (\%), unless otherwise indicated. IgG: immunoglobulin G. 
Table 2. Correlation coefficients between the components of the rheumatoid arthritis disease activity index and serum IgG (total) and IgG4 levels and the IgG4/lgG ratio

\begin{tabular}{|c|c|c|c|c|c|c|c|}
\hline Variable & $28 \mathrm{TJC}$ & $28 \mathrm{SJC}$ & PtGA & ESR & CRP & DAS28-ESR & DAS28-CRP \\
\hline Age & 0.146 & 0.126 & 0.089 & 0.195 & 0.188 & 0.154 & 0.159 \\
\hline Diseaseduration & $-0.213^{*}$ & $-0.208 *$ & $-0.235^{*}$ & -0.116 & -0.052 & $-0.202^{*}$ & $-0.238^{*}$ \\
\hline Serum IgG & 0.19 & 0.179 & $0.343^{* *}$ & $0.33^{* *}$ & 0.145 & $0.35^{* *}$ & $0.294 * *$ \\
\hline Serum IgG4 & 0.15 & 0.151 & 0.174 & $0.262^{*}$ & 0.109 & $0.245^{*}$ & 0.193 \\
\hline lgG4/IgG ratio & 0.101 & 0.099 & 0.047 & 0.188 & 0.054 & 0.144 & 0.82 \\
\hline
\end{tabular}

IgG: immunoglobulin G, 28TJC: 28 tender joint counts, 28SJC: 28 swollen joint counts, PtGA: patient global assessment of disease activity, ESR: erythrocyte sedimentation rate, CRP: C-reactive protein, DAS28: disease activity score-28. ${ }^{*} \mathrm{p}<0.05,{ }^{* *} \mathrm{p}<0.01$.

to the Spearman's analysis (Table 2), the significant correlations were found between serum IgG4 levels and DAS28ESR ( $r, 0.245 ; p=0.016)$, and between serum IgG4 levels and ESRs (r, 0.262; $\mathrm{p}=0.010$ ); a significant correlation was not observed between the IgG4/total IgG ratio and disease activity.

\section{DISCUSSION}

This study found elevated serum IgG4 levels in6.3\% (6/96) of patients with RA and in $10.7 \%$ (3/28) of patients with HDA; previous studies have reported elevated serum IgG4 levels in approximately $17.2 \% \sim 46 \%$ of patients with RA $[9,11,12]$. In healthy people, IgG4 makes up approximately $1 \% \sim 4 \%$ of the total IgG, making it the smallest IgG subclass $[4,13]$. Despite RA not being considered an IgG4-RD, we evaluated the role of IgG4 in this condition as it is elevated in certain patients. Previous studies on serum IgG4 levels in patients with RA have used a serum IgG4 level $>135 \mathrm{mg} / \mathrm{dL}$ as a diagnostic criterion for IgG4-RD $[14,15]$. Three methods of measure exist for determining IgG4 levels: nephelometric assay, enzyme-linked immunosorbent assay, and radial immunoassay [16], with the nephelometric assay (used in the present study) considered the most accurate.

We found a positive correlation between serum IgG4 levels and DAS28-ESR. A previous study compared serum IgG4 levels in patients with remission, LDA, MDA, and HDA, according to their DAS28 activity. In that study, higher IgG4 levels were also observed in patients with higher disease activity. We showed a correlation between DAS28 levels and serum IgG4 levels, suggesting that serum IgG4 levels might function as a disease activity marker. Previous studies in patients with RA have focused on the IgG4 autoantibodies created in response to specific antigens [17-19]. These autoantibodies seem to affect RA pathogenesis and play a partially protective role; however, their primary role appears to be pathogenic [20].

The present study has various limitations. First, the study was small, involving only 96 patients with RA. Further investigations involving more patients are required to determine the clinical significance of IgG4 levels in patients with RA. Second, the levels of IgG4 autoantibodies against rheumatoid factor and anticyclic citrullinated peptide were not measured together. Further studies are required to determine the correlation between the serum IgG4 levels and these autoantibodies to improve our understanding of role of IgG4 in RA pathogenesis.

\section{CONCLUSION}

Contrary to our expectations and the results of previous studies, only a small number of patients with RA had elevated serum IgG4 levels. However, serum IgG4 values were correlated with DAS28-ESR. Therefore, serum IgG4 levels may be useful for evaluating disease activity in patients with RA.

\section{ACKNOWLEDGMENTS}

The biospecimens for this study were provided by the Keimyung University Dongsan Hospital Korea Regional Biobank, a member of the National Biobank of Korea, which is supported by the Ministry of Health and Welfare. Financial support for this study was received from the 2016 SAMSUNG Eye Hospital Grant, Daegu Medical Association Dongwon grant, and the National Research Foundation of Korea (NRF) Grant funded by the Korean Government (MSIP) (no. NRF-2018M3C1B7020722). 


\section{CONFLICT OF INTEREST}

No potential conflict of interest relevant to this article was reported.

\section{AUTHOR CONTRIBUTIONS}

J.B.J., C.N.S. conception and design of study. S.H.K., J.M.K. acquisition of data. H.J.J., J.B.J. analysis and interpretation of data. S.H.K., C.N.S. drafting the manuscript. All authors approved the final manuscript.

\section{REFERENCES}

1. Firestein GS. Evolving concepts of rheumatoid arthritis. Nature 2003;423:356-61.

2. Aletaha D, Neogi T, Silman AJ, Funovits J, Felson DT, Bingham CO 3rd, et al. 2010 Rheumatoid arthritis classification criteria: an American College of Rheumatology/ European League Against Rheumatism collaborative initiative. Arthritis Rheum 2010;62:2569-81.

3. Sung YK, Cho SK, Kim D, Yoon BY, Choi CB, Cha HS, et al. Factors contributing to discordance between the 2011 ACR/ EULAR criteria and physician clinical judgment for the identification of remission in patients with rheumatoid arthritis. J Korean Med Sci 2016;31:1907-13.

4. Aalberse RC, Stapel SO, Schuurman J, Rispens T. Immunoglobulin G4: an odd antibody. Clin Exp Allergy 2009;39: 469-77.

5. Zhang H, Li P, Wu D, Xu D, Hou Y, Wang Q, et al. Serum IgG subclasses in autoimmune diseases. Medicine (Baltimore) 2015;94:e387.

6. Umehara H, Okazaki K, Masaki Y, Kawano M, Yamamoto $\mathrm{M}$, Saeki $\mathrm{T}$, et al. Comprehensive diagnostic criteria for IgG4-related disease (IgG4-RD), 2011. Mod Rheumatol 2012; 22:21-30.

7. Okazaki K, Uchida K, Ikeura T, Takaoka M. Current concept and diagnosis of IgG4-related disease in the hepato-bilio-pancreatic system. J Gastroenterol 2013;48:303-14.

8. Deshpande V, Zen Y, Chan JK, Yi EE, Sato Y, Yoshino T, et al. Consensus statement on the pathology of IgG4-related disease. Mod Pathol 2012;25:1181-92.
9. Yamamoto M, Tabeya T, Naishiro Y, Yajima H, Ishigami K, Shimizu Y, et al. Value of serum IgG4 in the diagnosis of IgG4-related disease and in differentiation from rheumatic diseases and other diseases. Mod Rheumatol 2012;22:41925.

10. Arnett FC, Edworthy SM, Bloch DA, McShane DJ, Fries JF, Cooper NS, et al. The American Rheumatism Association 1987 revised criteria for the classification of rheumatoid arthritis. Arthritis Rheum 1988;31:315-24.

11. Lin G, Li J. Elevation of serum IgG subclass concentration in patients with rheumatoid arthritis. Rheumatol Int 2010;30: 837-40.

12. Chen LF, Mo YQ, Ma JD, Luo L, Zheng DH, Dai L. Elevated serum IgG4 defines specific clinical phenotype of rheumatoid arthritis. Mediators Inflamm 2014;2014:635293.

13. Engelhart S, Glynn RJ, Schur PH. Disease associations with isolated elevations of each of the four IgG subclasses. Semin Arthritis Rheum 2017;47:276-80.

14. Ebbo M, Grados A, Bernit E, Vély F, Boucraut J, Harlé JR, et al. Pathologies associated with serum IgG4 elevation. Int J Rheumatol 2012;2012:602809.

15. Wang L, Chu X, Ma Y, Zhang M, Wang X, Jin L, et al. A comparative analysis of serum IgG4 levels in patients with IgG4-related disease and other disorders. Am J Med Sci 2017; 354:252-6.

16. Sun W, Gao RF, Chen Y, Su YY, Dong LL. Measurement of serum IgG4 levels by an established ELISA system and its clinical applications in autoimmune diseases. J Huazhong Univ Sci Technolog Med Sci 2013;33:611-4.

17. Engelmann R, Brandt J, Eggert M, Karberg K, Krause A, Neeck G, et al. IgG1 and IgG4 are the predominant subclasses among auto-antibodies against two citrullinated antigens in RA. Rheumatology (Oxford) 2008;47:1489-92.

18. Bos WH, Bartelds GM, Vis M, van der Horst AR, Wolbink GJ, van de Stadt RJ, et al. Preferential decrease in IgG4 anti-citrullinated protein antibodies during treatment with tumour necrosis factor blocking agents in patients with rheumatoid arthritis. Ann Rheum Dis 2009;68:558-63.

19. Wang W, Li J. Identification of natural bispecific antibodies against cyclic citrullinated peptide and immunoglobulin G in rheumatoid arthritis. PLoS One 2011;6:e16527.

20. Pan Q, Lan Q, Peng Y, Cai J, Zheng J, Dickerson C, et al. Nature, functions, and clinical implications of IgG4 autoantibodies in systemic lupus erythematosus and rheumatoid arthritis. Discov Med 2017;23:169-74. 